\title{
The Utilization of the National Qualifications Framework Level Descriptors as Criteria for Assessing Prior Experiential Learning to Access to Higher Learning Institutions of Namibia
}

\author{
Lydia Shaketange, Alex Kanyimba \\ Faculty of Education, University of Namibia, Namibia \\ Email:1shaketange@unam.na, akanyimba@unam.na
}

How to cite this paper: Shaketange, L. and Kanyimba, A. (2017) The Utilization of the National Qualifications Framework Level Descriptors as Criteria for Assessing Prior Experiential Learning to Access to Higher Learning Institutions of Namibia. Open Journal of Social Sciences, 5, 288-299. https://doi.org/10.4236/jss.2017.510025

Received: September 15, 2017

Accepted: October 28, 2017

Published: October 31, 2017

Copyright $\odot 2017$ by authors and Scientific Research Publishing Inc. This work is licensed under the Creative Commons Attribution International License (CC BY 4.0).

http://creativecommons.org/licenses/by/4.0/

\begin{abstract}
The assessment of experiential learning is the process of identification, articulation and legitimization of learning gained from years of work experience. The aim of this paper is to explore the utilization of level descriptors as criteria for assessing the prior experiential learning of candidates who aspire to access higher education. The recognition of the prior learning (RPL) concept has been embraced in education policies around the world as a process that assesses and recognises non-formal and informal learning attained by an individual, to determine the level of competency achieved. However, the implementation of the concept by higher education institutions remains insignificant. Some reasons cited relate to the method used to assess learning in admission tests, such as the recall of subject knowledge. It is argued in this paper that the alignment of individuals' learning evidence with the National Qualifications Framework's level descriptors is critical as an alternative route of assessment. The assessment method based on alignment of level descriptors allows for self-exploration and deeper reflection of own learning, giving insight not only into the self but also for the benefit of the host institution. Host institutions benefit from RPL, not only by choosing qualified candidates to enter their programmes, but also by having candidates who lived the experience and have understanding of the field of study. The alignment method is perceived to be a reflective strategy of assessing experiential learning and is born out of the transformative process which encourages deep learning and portrays the quality of potential candidates. Studies have shown no significant differences between the performances of students who accessed higher learning through Grade twelve certificates and those who accessed through RPL. Therefore, when an appropriate and robust method is adopted, RPL is feasible and beneficial to all involved.
\end{abstract}




\section{Keywords}

Experiential Learning, Recognition of Prior Experiential

Learning, Non-Certificated Learning, Alignment of Learning,

Level Descriptors, Reflective Learning

\section{Background}

It is feasible to access educational programmes through the Recognition of Prior Learning (RPL), provided that diverse, reliable and valid methods of assessment are devised. RPL is an assessment strategy in which knowledge and skills acquired through non-formal ways of learning or through experiential events can be identified, acknowledged, assessed and validated [1]. The strategy could be beneficial to employees who have been out of the education system for a long time and who want to return to the higher education system. One of the strengths of RPL is the potential to challenge traditional procedures for admitting candidates to higher education which tend to be based solely on certification. Even where work experience is a requirement for eligibility to admission tests to access higher education, in most cases admission tests require that candidates recall prior formal knowledge [2]. RPL is critical in widening access by providing an opportunity to candidates to use prior learning to articulate non-certificated knowledge, skills and competences acquired and to acknowledge the relevance of work-based knowledge. Tabatadze and Gorgadze [3] suggest that universities and colleges should shift away from the elitist criteria of admission to the inclusive criterion of education because it embraces access and equity. Therefore, RPL provides an opportunity for individuals who do not have formal qualifications to enter higher education institutions on the basis of learning derived from an accumulated amount of work experience [4].

The World Bank [5] and Dyke [6] report that individual workers in the job markets are usually compelled by their own dispositions to continuously review their knowledge and upgrade their skills and experiences in light of new developments and changing labour situations. This transformation of workers' knowledge and skills into new work categories has necessitated the demand for RPL. In addition, the International Conference on Adult Education [7] called for countries of the world to enact laws and policies that embrace flexibility and reduce barriers to access institutions of higher learning. The Conference advocated the commitment to develop and improve structures and mechanisms for the assessment, recognition, validation and accreditation of all forms of learning by establishing equivalency frameworks). Agenda 2030 also calls for the assurance of equal access to all levels of education and the expansion of learning opportunities for all [8]. Given these calls, the provision of opportunities for inclusive education has been created, which culminates in the need to assess learning previously obtained and non-certificated for all those who wish to access education- 
al programmes.

The RPL concept has been embraced in education policies around the world as a strategy to recognise the uncertificated non-formal and informal learning to access academic programmes. For example, the Australian Qualification Frameworks embraced the RPL concept for two main reasons: As a pathway for admission to any qualification at any level and as a government policy that encourages a wider population to achieve high levels of education [9]. Australia encourages employees to continue studying while working. This addresses the inclusiveness of all workers who aspire to access higher education. To achieve this, Australian educational institutions have also been encouraged to offer multiple pathways to allow wider access of qualified candidates to their learning programmes, and RPL is one of these pathways [9]. In the United Kingdom (UK), RPL has also been embraced as a way of recognising lifelong learning and as a means to enhance social inclusion through access to academic and vocational qualifications [10].

Despite the fact that RPL is internationally recognised, the implementation thereof by higher education institutions is minimal. In fact, Garnett and Cavaye (9) highlight some limitations to demonstrate this reality. Firstly, the authors report that universities that offer RPL also acknowledge lack of marketing opportunities for RPL. Secondly, the experts responsible for assessing RPL have found few academics to be available to support the RPL concept. Moreover, the process is labour-intensive, and doubts exist pertaining to the quality, reliability and validity of learning acquired from experience. However, the onus always rests on the host institution to assess the mechanisms of assessing learning from experience and to protect and ensure the quality and integrity of its assessment process.

In Namibia, the National Qualifications Authority (NQA) recognises learning acquired through non-formal pathways as long as such learning can be justified. The Namibia Qualification Framework (NQF) was developed and structured around a set of levels defined by descriptors by which to measure the learning outcomes and to provide the means to relate these learning outcomes to each other. In this way, the concept of hierarchy becomes the fundamental dimension on which NQF is based [11]. The concept of hierarchy represents a system of ranking the relative difficulty of the learning acquired. Level descriptors area classification system which defines the complexity and in-depth requirements of learning. They describe and specify the subject areas to be covered by the candidate and classify the scope and complexity of learning outcomes to be achieved [11]. The level descriptors are seen as a unifying tool for measuring learning that has been attained by a candidate at a particular level. This is then used to benchmark learning acquired from the Namibian-based education institutions as well as those attained from non-Namibian institutions. The utilization of the National Qualifications Framework level descriptors as assessment criteria for Prior Experiential Learning to access educational programmes in higher learning institutions of Namibiais by itself a conscious exercise, where candidates engage 
with experience, interpret it and make sense of what they have learnt from it. In light of the above, this paper argues in favour of the potential of the level descriptors to evaluate the scope and complexity of prior learning evidence presented by RPL applicants seeking access to higher education.

The data presented in this paper was obtained by means of documentation. The main documents reviewed include secondary data that relate to the recognition of prior learning. The researchers also reviewed the documents from the Ministry of Education dealing with the NQF level descriptors.

This paper is divided into five parts. The first part addresses the conceptualisation of experiential learning; this is followed by experiential learning through reflective methods. Next is the discussion pertaining to the assessment of RPL in higher education, and the fourth part discusses the benefits of utilizing the NQF descriptors as assessment criteria. The final part contains the conclusions and recommendations for utilizing the NQF level descriptors in Namibian higher education.

\section{Conceptualising Experiential Learning}

Experiential learning connotes skills, knowledge and competences which candidates have acquired on the job or through experience [1]. Garnett and Cavaye [9] have explained that experiential learning can also be derived through formal learning routes where organised and certificated learning is awarded. It can also be acquired from non-formal learning routes where organised and uncertificated learning is attained. Moreover, experiential learning can be acquired informally through unplanned and uncertificated learning. In terms of the UK, Garnett and Cavaye [9] explain that the RPL concept is perceived not only as a way of recognising lifelong learning, it is also about enhancing the strategy for social inclusion because it provides and extends access to academic and vocational qualifications for those who might have been excluded through lack of formal qualifications. In this regard, prior learning is based on credit awarded when upon demonstration of evidence, it shows that the standards required to enter an institution have been met due to learning attained as a result of undertaking a particular job, or attendance of workshops or community participation. For example, learning that a project manager has attained over the years could be demonstrated when the project manager proves that he or she possesses knowledge of managing a project equivalent to the scope and complexity of knowledge required to access a study programme. Therefore, assessors need to make a clear distinction between events of experience and evidence of learning acquired from such events.

Berglund and Andersson [12] clarify that knowledge and skills developed in the workplace are seldom documented or even acknowledged. Therefore, the RPL concept brings on board the recognition of competence that may not have been highlighted previously. Berglund and Andersson maintain that the knowledge and skills achieved and developed in the workplace need to be documented and evaluated through a structured process of assessment. The outcome of this 
assessment should show the level of learning acquired and this could be used to gain access to higher educational institutions or for promotion requirements in the workplace.

\section{Experiential Learning through Reflective Methods}

The alignment of experiential learning to level descriptors advocated in this paper is framed according to Kolb's experiential learning theory. Accordingly, the Kolb's theory of experiential learning presents reflective skill as critical to the learning process. Figure 1 presents four stages of the experience learning theory:

The reflective process sees learning as a way of gaining knowledge, the processing of information and making connections. Learning through the reflective process encourages the development of thinking abilities and allows the integration of new experience in light of previous knowledge. The Scottish Credit and Qualifications Framework Partnership [10] argue that the reflective method of assessment promotes a transformative process that assists the development of new knowledge, skills and perceptions. Given this view, the authors maintain that the assessment of experiential learning should be based on reflective methods in which a candidate engages with the experience, reflects on the experience, and makes connections and generalisations that scaffold into patterns of new knowledge.

Equally, assessors need to have the ability to identify knowledge, skills and competence emanating from the description of learning events undertaken in contexts. The reflective learning process is significant because it provides an opportunity for candidates to learn to describe the experience, evaluate the activities undertaken, analyse the outcome of those activities and judge whether such outcome equates the level of knowledge required to access higher education institutions. The authors of this paper believe that NQF level descriptors have the potential to measure and classify the complexity and in-depth requirements of learning.

\section{The Assessment of RPL in Higher Education}

The notion advanced by the authors of this paper rests on the utilization of the

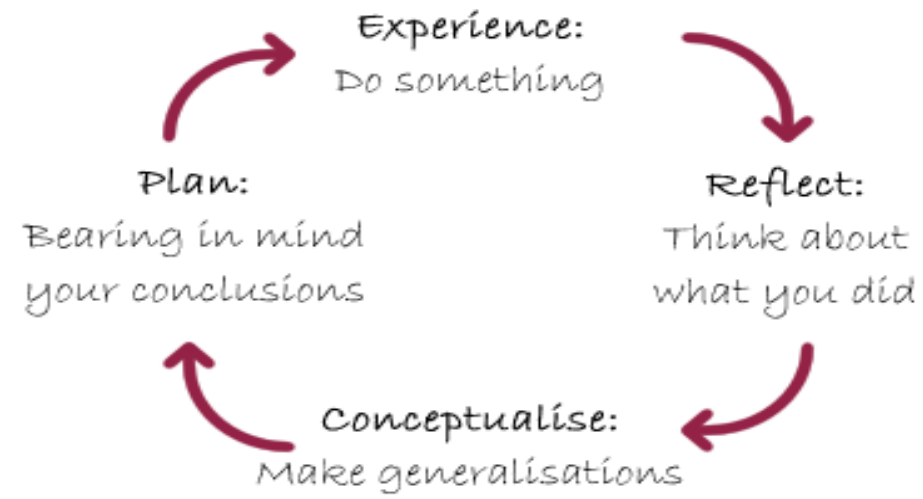

Figure 1. The four stages of the experiential learning theory [10]. 
NQF level descriptors as assessment criteria for assessing Prior Experiential Learning to access educational programmes in Namibia. The purpose of RPL is to provide alternative assessment routes for learning acquired outside the formal education system. RPL is therefore advocated as an assessment alternative for employees with prior experiential learning seeking entry into Namibian institutions of higher learning.

The literature reveals that international practices among higher education institutions have in the past embraced the use of RPL to enhance access, but the take-up rate has been modest (9). Garnett and Cavaye (9) highlight some limitations that seem to constrain the implementation of RPL in higher education institutions. These limitations include the marketing of RPL as a means of admission. It is argued that even institutions that testify to having offered RPL services acknowledge that the opportunity to inform potential participants about such a service has not always been there. It seems that RPL service claims have often concentrated on a few individual staff members and not on the entire institution. The academics in such institutions have claimed that the RPL is labour-intensive in terms of assessment and not cost-effective for the institution. Moreover, there are lingering doubts about the reliability of RPL assessment tests and the validity of the learning assessed. This combination of factors limits the effective practice of RPL in higher education.

Given the amount of limitations highlighted in the literature, institutions need to explore strategies that would curb the vicious circle of such limitations. It is the responsibility of every higher education institution to enhance the academic credit of assessments that they award in its name, and they must take full responsibility to ensure that all learning for which credit is awarded is assessed with equal rigour [9]. This means the same strategies used in assuring quality in learning attained through programmes should be applied equally to the RPL process. The role of higher education is to determine and specify what knowledge or skills are assessed through RPL. Inability to distinguish the knowledge assessed through RPL leaves doubts as to whether assessors do indeed assess knowledge from experiences or do they simply demand that candidates relate the events in which they participated.

The literature describes two forms of credit that higher education institutions could award: the credit-specific and general credits awards [1] [9] [13]. Garnett and Cavaye [[9] p. 31] explain that specific credit is awarded to learning where there is a direct match between the learning evidence and the learning outcomes of specified modules. The general credit is awarded to learning where no specific match is made but the learning achieved is at a higher education level. One example that can be cited is that of the Middlesex University which focuses on the facilitation of learning reviews of general credit. According to Garnett and Cavaye [9], the aforementioned example seems to demonstrate a shift in assessment from those that only recognise learning that closely matches existing validated programmes to an assessment that is flexible, open and takes into account 
various forms of learning. It is up to the higher education institution to specify the knowledge they assess and the credit they would award. Universities around the world are shifting towards the assessment of general credits which accommodate and recognise learning achieved outside the university. Therefore, utilization of the NQF level descriptors concurs with the international demands for the assessment of general credits in higher education.

Learning from experience is beneficial to higher education. It allows candidates to explore, analyse and interpret the skills, knowledge and competences that emerge from the events undertaken. This is in contrast to reciting the contents of prior learnt subject knowledge acquired in previous education. The reflective ability implies that those who go through the RPL process are perceived as the most qualified candidates to enter higher education, since they are mature and have a sense of understanding the kind of additional learning they are seeking from education.

\section{The Significance of the Level Descriptors for the RPL Process}

The Namibia NQF's level descriptors are described as the relative level that could be used to maintain consistency in benchmarking learning [14]. The NQF further specifies that level descriptors do not usually set out requirements about content and delivery method but define the expected level of complexity required at a specific level. They express the relative size of each qualification, such as certificates or diplomas, in an effort to encourage consistency when expressing the content area or equivalent level of learning covered by any specified qualification. It is the expectation that is placed on NQF level descriptors to measure and pronounce the relative size of a qualification that makes NQF level descriptors potential assessment criteria for experiential learning. Equally, the NQF level descriptors are necessary in the RPL assessment process not to examine what content is learnt or how it was learnt, but to transparently determine whether the learning evidence submitted on what was learnt meets the standard, volume and complexity at the required NQF level to warrant admission to Namibian institutions of higher learning.

Table 1 illustrates some level descriptors that can be used to maintain consistency in the benchmarking of learning to gain entrance to undergraduate programmes at Namibian institutions of higher learning.

Namibia has 10 level descriptors which could be used to measure, classify and interpret learning acquired by candidates seeking entry to institutions through RPL services. Most institutions of higher learning in the country offer alternative admission routes to candidates who have completed Grade 10 and have had three to five years of working experience. Grade 10 learning is equivalent to completion of NQF level three. The NQF [[14], p. 16] stipulates that the Namibian Senior Secondary Certificate (NSSC) is a NQF level 3 qualification. In most cases a three-year diploma qualification begins at NQF level 4 . Thus, it can be 
Table 1. Level descriptors 3 and 4 of the Namibia national qualifications framework.

Employing a broad knowledge base incorporating some theoretical concepts or in-depth applied knowledge and skills in a specific area. Analytical interpretation of information. Making informed judgement and offers a range of sometimes innovative responses to concrete but often unfamiliar problems.

4 Carry out processes that require a wide range of technical or scholastic skills and/or that offer a considerable choice of procedures. Often employed in a variety of familiar and unfamiliar contexts.

Applied in self-directed activity under broad guidance and evaluation. Complete responsibility for quantity and quality of output, with possible responsibility for the quantity and quality of the output of others.

Employing some relevant theoretical knowledge and interpretation of available information. Uses discretion and judgement over a range of known responses to familiar problems.

3 Carry out processes that require a range of well-developed skills and offer a significant choice of procedures within a range of familiar contexts.

Applied in directed activity with some autonomy. Under general supervision and quality checking, though with significant responsibility for the quantity and quality of output, with possible responsibility for the output of others.

Source: Kronner [[15], p. 34].

assumed that graduates of NSSC who have completed NQF level 3 can access a programme of study at NQF level 4 . The interest of institutions therefore is to assess candidates who aspire to join diploma programmes against NQF level 3. This is to ascertain that such candidates indeed possess knowledge, skills and competence equivalent to NQF level 3 and that, if successfully assessed, they should be allowed access to programmes of study at NQF level 4. Similarly, candidates who want admission to undergraduate degree programmes will be assessed to determine whether their scope and depth of knowledge is equivalent to NQF Level 4 to warrant admission to NQF level 5 programmes.

The discussion of this paper is centred on the assessment of prior non-certificated learning for candidates who want to join study programmes at NQF level 4 and NQF level 5. Table 1 above presents the NQF level descriptors at level 3 and 4 since these levels constitute the discussion of this paper. The learning assessed is neither grounded on what is learned in class nor on how or where it was learnt; rather, it is grounded on whether what was learnt (irrespective of place and method) reflects the standard and volume of the required learning outcomes. Heron and Lister [11] argue that the complexity of learning is conveyed in the level descriptors within which learning outcomes are measured and related to each other. The potential of comparing and benchmarking evidence of learning to the NQF level descriptors is the discussion being advanced in this paper. The RPL concept views knowledge as a valuable commodity that can be accepted in its own right within its context of practice [1] [16]. This assertion is at odds with the current admission tests usually given at Namibian institutions of higher learning. The current assessment methods engage the candidates to recall previous subject knowledge. The context of practice of the required knowledge is derived through standardised tests given at admission and 
selection assessments. One of the weaknesses of the standardised tests is that it assesses knowledge, competencies and skills which are normally designed, administered, scored and interpreted in the same way, regardless of when, where and how such knowledge was acquired. This method denies candidates the mandate to engage with the tools for reflective thinking and the contribution to the self-consciousness of the individual. The argument held by Tabatadze and Gorgadze [3] is that universities and colleges need to shift from elitist rote assessment methods that require pure subject proficiencies, to inclusive and flexible methods of assessment. This assertion implies that institutions of higher learning need to opt for the assessment strategy that allows candidates to engage with the experience. This engagement illustrates the degree to which a candidate has acquired learning rather than being obliged to answer correctly to set questions. The level descriptors do not precisely measure the content achieved, but they provide an indication of the amount of learning acquired. The candidate will then satisfy level 3 requirements by exhibiting the application of directed activity within the area of study. The candidate will show, with evidence, aspects in his or her learning which include autonomous learning or decision. The candidate will eventually be required to sort out which of the learning outcomes is relevant to the programme of study applied for, describe and categorise skills and abilities and make decisions on how the evidence of learning will be presented. In all the activities to be undertaken, the subject of performance is the candidate and not the tutor or a marking guide.

\section{Conclusions and Recommendations for Utilizing the NQF Descriptors in Namibia}

The authors of this paper concur with Michelson et al. [17], who argue that the value of the RPL depends not only on the experience of the subject matter but also on the candidate's method of interpreting such learning. The authors extend the current knowledge base by suggesting the assessment of RPL through the process of aligning the evidence of knowledge, skills and competence to NQF level descriptors. This alignment is the process of matching the candidate's prior non-certificated learning against the NQF level descriptors. The alignment need not be based on learning outcomes for specific modules but rather on the learning achievements acquired either in the work place or any uncertificated learning. Such learning should match the level described in the NQF level descriptors for the level completed. The level descriptors allocate a level to a qualification, such as a certificate, diploma or degree. Seeking admission to a programme therefore implies that the candidate has fulfilled the requirements needed to access the desired programme. The NQF level descriptors would ascertain that the learning described by the candidate meets the level required to access a programme. Michelson et al. [17] highlight that RPL assessment in most higher education programmes would be successfully introduced when linked to subjects with a clearly professional focus. However, the view advocated in this paper differs from the link of learning to subjects. The ideal strategy advanced here im- 
plies that the NQF level descriptors become the standards against which learning evidence is matched. The levels as indicated in Table 1 above require the following:

1) NQF level 3:

- Application of directed activities with some autonomy.

- Carrying out processes that require a range of well-developed skills and choice of procedures.

- Employment of theoretical knowledge and interpretation of available information.

2) NQF level 4:

- Broad guidance and evaluation of responsibility for quality and quantity.

- Technical and scholastic skills.

- In-depth applied knowledge skill, analysis and interpretation of information.

The strength of the NQF level descriptors lies in the fact that they are broad to allow diverse interpretations of learning. Level 3 requires directed activities with some autonomy. The descriptors do not specify the kinds or content of activities to be conducted and the method by which such activity is performed, but rather any learning (irrespective of context of production) that exhibits application of directed activity with some autonomy. Autonomy can mean a candidate's range of skills and ability which allows him or her to choose procedures. This content is exhibited in the learning evidence submitted by the candidate. Employing some theoretical knowledge in the profession implies the candidate's ability to relate his or her learning to theory acquired through the understanding of notions that grew out of practice. For instance, a candidate can describe how adults learn and what happens if a learning situation is not conducive to adults' learning. Learning extracted from scenarios and case studies should show knowledge and an ability of theoretical understanding to qualify a candidate to access NQF level 3 programmes. The same applies to NQF level 4. It is the responsibility of quality and quantity, technical and scholastic skills as well as in-depth applied knowledge with interpretation of information that can qualify a candidate to access NQF level 5 programmes. These level descriptors give a clear directive as to the requirement of the scope, in-depth and quality of knowledge required. Such requirements would be difficult if not impossible to attain within the current test methods of subject assessment, where the content of the test is derived from a specific book, towards a specific activity and context. The correct answers to every question are determined by the examiner and the work of the assessor is to benchmark candidates' answers against the answers given in the tutor's marking guide. That system differs from the view advocated here.

Utilizing the level descriptors implies that the candidate has to engage, reflect and think what he or she has achieved. The candidate gathers the evidence and presents such evidence for assessment. In the process of gathering evidence of learning, the candidate makes decisions and choices of what learning meets the descriptions of learning given in the descriptors at a specified level. In other words, the curriculum to be assessed is compiled purely by the candidate rather 
than by some authorities in the institution. The candidate owns the content in the portfolio of evidence. Assessors will assess learning that inductively emerged out of the candidate. This knowledge is not predictive but the actual fact of learning attained.

It can therefore be argued that candidates who go through the process of RPL using the alignment to NQF level descriptors are much more qualified to enter higher learning. Such candidates would enter educational institutions knowing what they want and how it can be achieved. The advocacy of aligning evidence to level descriptors does not insinuate that alignment is the sole reliable method of assessment. The argument is that it constitutes the most rigorous and robust way of maintaining credibility in the assessment. This is because assessment is done against the hard evidence gathered, arranged and analysed by a candidate. In other words, assessment is done against what the candidate possesses, and not against prescriptions of module learning outcomes. The level descriptors do not stipulate the precise content that students should have acquired, but rather indicate the scope and depth of learning required at a specific level, irrespective of the field of study. Therefore, any academic programme can be assessed by utilising level descriptors. Institutions of higher learning ought to support this assessment method, as candidates who come out of the process prove to have understanding of the knowledge and skills they have acquired, and they know precisely what amount of learning that they still have to acquire in order to fill the gap in their knowledge base. If only all candidates could be subjected to this assessment, institutions of higher learning would have well-equipped individuals focused and ready to study. Garnett and Cavaye [9] advise that universities are unique because their function not only entails teaching, research and community service, but also carries the duty to formally recognise learning achievements. It is therefore imperative that universities and other education programmes acknowledge the diversity in learning and thus the diverse assessment thereof.

\section{Conclusion}

This paper has presented a conceptual outline for the utilization of the National Qualifications Framework Level Descriptors as criteria for assessing Prior Experiential Learning to gain access to educational programmes in Namibia. It is argued that access to educational programmes through the recognition of prior non-certificated learning is feasible provided that diverse, reliable and valid methods of assessment are devised. The assessment of prior non-certificated learning is indispensable as it widens access to institutions of higher education. This assessment is democratic and promotes inclusiveness in education. It is noted that the assessment of non-certificated learning could be feasible when rigorous assessment strategies are put in place and embraced by all those involved in the process. Therefore, the argument presented in this paper rests on aligning the prior experiential learning with the level descriptors. Level descriptors are seen as national indicators that define the outcomes of learning attained, the depth of learning and the complexity of learning achieved. The level descriptors as me- 
thod of assessment would promote transparency in the assessment process to facilitate transferability of RPL graduates between institutions.

\section{References}

[1] Harris, J. (2000) RPL: Power Pedagogy and Possibility: Conceptual and Implementation Guide. Human Sciences Research Council (HSRC), Pretoria.

[2] Shaketange, L. and Kanyimba, A. (2016) The Kind of Knowledge Assessed through Mature Age Entry Admission Tests in Namibian Institutions of Higher Learning: Case Study of the University of Namibia and the Polytechnic of Namibia. International Journal of Higher Education, 5, 63-74.

[3] Tabatadze, S. and Gorgadze, N. (2017) Affirmative Action Policy in Admissions Systems of Higher Education of Post-Soviet Georgia. Journal of Applied Research in Higher Education, 9, 363-7003. https://doi.org/10.1108/JARHE-03-2016-0020

[4] Scottish Credit and Qualifications Framework Partnership (2010) Facilitating the RPL Toolkit. http://scqf.org.uk/content/files/RPL Toolkit FINAL -May 2010.pdf

[5] World Bank Report (2004) Lifelong Learning in the Global Knowledge Economy: Challenges for Developing Countries. The World Bank, Washington DC.

[6] Dyke, M. (2009) An Enabling Framework for Reflective Learning: Experiential Learning and Reflexivity in Contemporary Modernity. International Journal of Lifelong Education, 28, 289-310. https://doi.org/10.1080/02601370902798913

[7] CONFINTEA V1. (2010) Final Report: Living and Learning for a Viable Future: The Power of Adult Learning. UNESCO Institute for Lifelong Learning, Paris.

[8] United Nations (2015) Agenda 2030 Transforming our World: The 2030 Agenda for Sustainable Development, A/RES/70/1. United Nations, New York.

[9] Garnett, J. and Cavaye, A. (2015) Recognition of Prior Learning: Opportunities and Challenges for Higher Education. Journal of Work-Applied Management, 7, 28-37. https://doi.org/10.1108/JWAM-10-2015-001

[10] Heron, G. and Lister, P.G. (2014) Influence of National Qualifications Frameworks in Conceptualising Feedback to Students. Journal of Social Work Education, 33, 420-434. https://doi.org/10.1080/02615479.2013.834322

[11] Namibia Qualifications Authority (NQA) (2006) Regulations for Setting up a National Qualifications Framework for Namibia. NQA, Windhoek.

[12] Berglund, L. and Andersson, P. (2012) Recognition of Knowledge and Skills at Work: In Whose Interest? Journal of Workplace Learning, 24, 73-84. https://doi.org/10.1108/13665621211201670

[13] Mankin, D. (2009) Human Resource Development. Online Resources Centre. Oxford University Press, Oxford.

[14] National Qualifications Framework (NQF) (2007) Regulations for Accreditation by the Namibia Qualifications Authority. NQA, Windhoek.

[15] Kronner, H. (2006) Articulation of Post-Primary Education \& Skills Development: National Qualifications Framework of SA, Namibia and Mauritius. UNESCO Regional Seminar on Secondary Education in Africa, Addis Ababa, Ethiopia.

[16] Osman (2003) The Recognition of Prior Learning and Emerging Field of Inquiry in South Africa. University of Watersrand, Johannesburg.

[17] Michelson, E., Mandell, A. and Contributors (2004) Portfolio Development and the Assessment of Prior Learning: Perspective, Model and Practice. 2nd Edition, Stylus Publish CLC, Sterling. 